Research Article

\title{
The irrational fixed dose combinations in the Indian drug market: an evaluation of prescribing pattern using WHO guidelines
}

\author{
Somesh P. Rayasam ${ }^{1}$, Sujata S. Dudhgaonkar ${ }^{2}$, Ganesh N. Dakhale ${ }^{1}$, \\ Rohan C. Hire ${ }^{1}$, Prashant S. Deshmukh ${ }^{1}$, Nilesh N. Gaikwad ${ }^{1}$
}

\author{
${ }^{1}$ Department of \\ Pharmacology, Government \\ Medical College, Nagpur, \\ Maharashtra, India \\ ${ }^{2}$ Department of \\ Pharmacology, Indira Gandhi \\ Government, Medical \\ College, Nagpur, \\ Maharashtra, India
}

Received: 5 June 2013

Accepted: 24 June 2013

*Correspondence to:

Dr. Somesh P. Rayasam,

Email:

drsrayasam@gmail.com

(C) 2013 Rayasam SP et al.

This is an open-access article distributed under the terms of the Creative Commons Attribution License, which permits unrestricted use, distribution, and reproduction in any medium, provided the original work is properly cited.

\begin{abstract}
Background: Evaluation of the pattern of fixed dose combinations (FDCs) prescribing amongst the practitioners in a tertiary care hospital in Central India.

Methods: Nine hundred and ninety four prescriptions, containing 639 FDCs were scrutinized in the tertiary care hospital. After excluding the total and the interdepartmental repetitions, the numbers of FDCs were 278, which were considered for final analysis. Inclusion criteria were FDCs from the major outpatient department (OPD) of the tertiary care hospital from January 2011 to December 2011. FDCs from the wards, casualty, infectious disease unit, intensive cardiac care unit (ICCU), tuberculosis and chest and HIV unit were excluded from the study. FDCs were analysed for the different pattern of prescribing and rationalism. Results were expressed as percentages.

Results: Out of 639 FDCs, the most commonly prescribed FDCs were B complex $(12.20 \%)$, pantoprazole plus domperidone $(9.55 \%)$ and amoxicillin plus clavulanic acid $(7.35 \%)$. Seventy percent of the FDCs were prescribed to the age group of 21-60 years. The FDCs were maximum from the department of medicine (25.59\%), followed by surgery $(15.47 \%$ ) and ENT $13.69 \%$. Out of 278 FDCs, only $5.4 \%$ were rational, and rest of the FDCs were irrational. Ninety five percent of all FDCs were brand names. The physicians were unaware of the active pharmacological ingredients (APIs) of $20.86 \%$ FDCs. Ninety two percent FDCs were available as over the counter (OTCs). Forty eight percent FDCs were costing from Rs. 0-50. There were $2.87 \%$ FDCs whose price was above Rs. 500.

Conclusions: Irrational FDCs are prescribed by all the departments. Physicians were ignorant about the essential drugs and FDCs. Patients didn't have access to rational medicines. Therefore, physicians and regulators should be alerted in time. Regulatory actions or government laws should be made mandatory. Availability and access to 348 essential medicines for basic health care should be the priority of the government. Implementation of central drug standard control organisations (CDSCO) guidelines on industries for manufacture of FDCs must be made compulsory.
\end{abstract}

Keywords: Fixed dose combination, Irrational, OTC drugs, Prescription analysis, WHO guidelines

\section{INTRODUCTION}

Fixed dose combinations (FDCs) is a combination product of two or more active pharmacological ingredients (APIs) in a single dosage form. In FDCs, drugs from different pharmacological groups having complementary mechanism of action should be combined. The FDC is an innovative product, the main advantages being increase in patient's compliance, decrease in pill burden, reduced complications and the cost. ${ }^{1}$ The safety profile of the established drugs changes when they are combined in a single formulation. There is a growing concern about the increasing number of irrational FDCs in the developing countries which impose unnecessary financial burden, increase the occurrence of adverse drug reactions, including allergy, hospitalization and ultimately reducing the quality of life. ${ }^{2}$ Combining two or more drugs in a single formulation causes changes in its efficacy, safety and bioavailability profile; hence FDCs are treated as new drugs.

The most of the popular and highly profitable FDCs, moving widely in the Indian drug market are analgesics, tonics, antibiotics, cough and cold preparations, 
multivitamins, iron preparations and antacids. The Indian laws are not properly defined to grant marketing approval by central or state drug controlling authorities, hence there is an increase in the number of irrational FDCs in the Indian drug market at an alarming rate. The concept of rational FDCs has not yet penetrated in the minds of physicians; hence evaluation is needed, as large numbers of FDCs are of little importance in terms of effective health care. Thus, it was considered worthwhile to evaluate the pattern of FDCs prescribing, in a tertiary care teaching hospital in Central India.

\section{METHODS}

It was a prospective observational study. This study was approved by the local institutional ethics committee and was carried out from January 2011 to December 2011 in a tertiary care teaching hospital. Study was conducted in the outpatient department (OPDs) of medicine, surgery, obstetrics and gynaecology, E.N.T, ophthalmology, orthopaedics and skin. All prescriptions over a period of 15 days in each OPD were analyzed. FDCs prescribed were recorded and evaluated for rationality. A total of 994 prescriptions were scrutinized. These 994 prescriptions contained 639 FDCs meant for oral use only. By excluding the repetitions, the total numbers of the FDCs from all the departments were 336. These 336 FDCs included interdepartmental repetitions, thus by excluding them; the total numbers of the FDCs were 278, which were considered as ' $n$ ' for further analysis. These FDCs were analyzed for rationality using WHO guidelines. The following guidelines were followed. ${ }^{3}$

The FDC was termed as rational if they had

1. APIs with complementary mechanism of action

2. Decrease the occurrence of resistance for antimicrobial agents (AMA)

3. Increase the efficacy of the combination

4. Decrease the occurrence of adverse drug reactions or toxicity

5. Increase the compliance of the drug therapy with decrease pill burden

6. Decrease the total cost of the therapy and

7. Dose of each API should be appropriate for defining or larger groups of populations. ${ }^{3}$

The FDC was termed as absurd if it shows ${ }^{4}$

1. No rationale or justification for combination

2. No increase in efficacy than individual drugs

The fixed dose combinations in our study were classified into 4 categories as rational, irrational, absurd and rejected or banned. ${ }^{4}$

Inclusion criteria were prescriptions from the outpatient departments. FDCs were later segregated. FDCs from the wards, casualty, infectious disease unit, intensive care unit, TB and chest department and HIV unit were excluded from the study. FDCs were analysed for the different pattern of prescribing and rationalism. The results were expressed as percentages.

\section{RESULTS}

The percentage of FDCs prescribed in different departments has been shown in Figure 1. Maximum FDCs were prescribed in medicine $(25.59 \%)$, followed by surgery (15.47\%), and ENT (13.69\%). Minimum FDCs were prescribed in the department of obstetrics and gynaecology (6.54\%). Categorization of the FDCs according to WHO guidelines for rationality is depicted in Figure 2. Out of 278 FDCs, only $5 \%$ were rational and $76.61 \%$ were irrational.

The comparison of the FDCs prescribed as brand names and generic names is shown in Figure 3. The majority of the FDCs $(95 \%)$ were prescribed by the brand names. The knowledge of the prescribers about the APIs of the prescribed FDCs is given in Figure 4. Prescribers were questioned about the APIs of the prescribed FDCs. Prescribers were questioned about the contents of the prescribed FDCs which were prescribed as brand names. It was found that they were unaware of the contents of $74.6 \%$ of FDCs. It is clear from the figure that physicians were aware of the APIs of the 140 FDCs, while they were unaware of the APIs of 57 FDCs. Over the counter cell (OTC) medications available as FDCs were $91.36 \%$ (Figure 5).

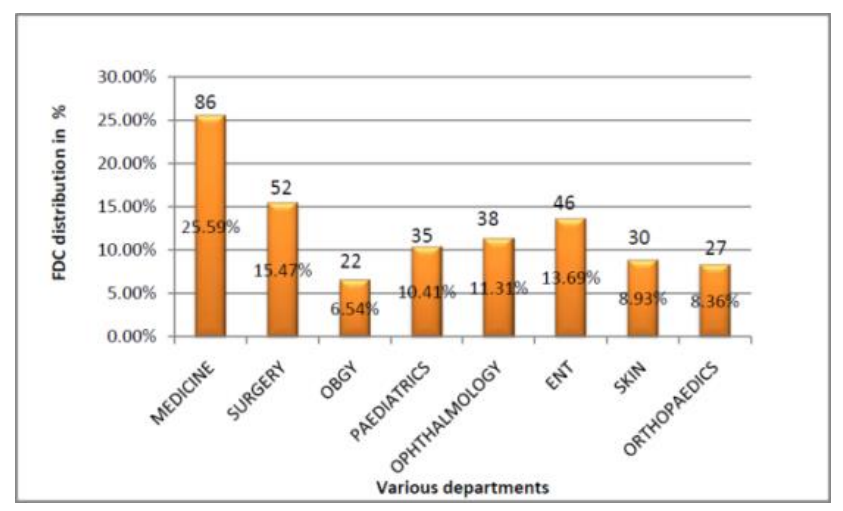

Figure 1: Total number of FDCs prescribed in different departments including inter-departmental repetitions. Values are expressed as percentages, $n=336$, $\mathrm{FDC}=$ fixed dose combination.

The pharmacological classes of FDCs prescribed with categorization as per WHO guidelines are shown in Table 1. From the total prescriptions analysed, FDCs of antimicrobial agents were found to be maximum i.e. 68 in number out of which only 6 were rational. The banned FDCs which were encountered in our study are depicted in Table 2. 


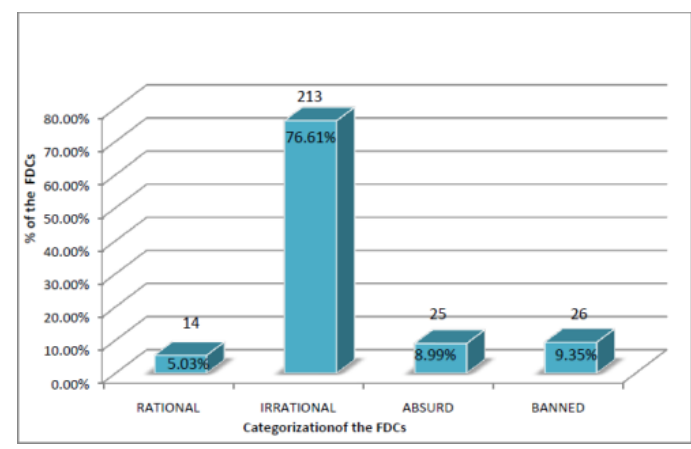

Figure 2: Categorization of the FDCs based on WHO criteria for rationality. Values are expressed as percentages, $\mathrm{n}=278, \mathrm{FDC}=$ fixed dose combination.

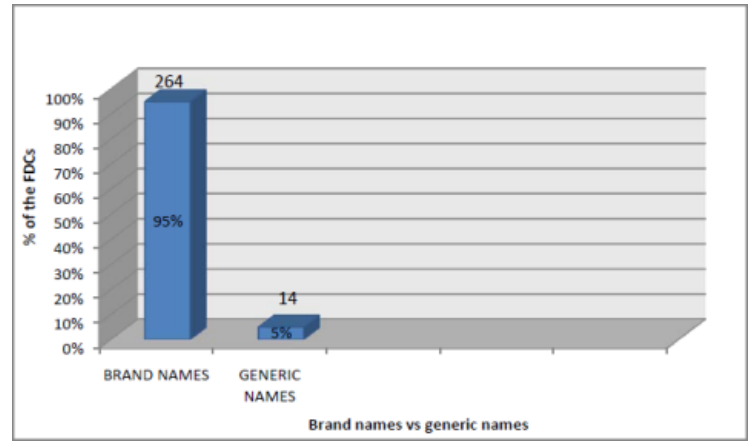

Figure 3: Comparison of FDCs prescribed as brand names and generic names. FDCs are expressed as percentages, $\mathrm{n}=278, \mathrm{FDC}=$ fixed dose combination.

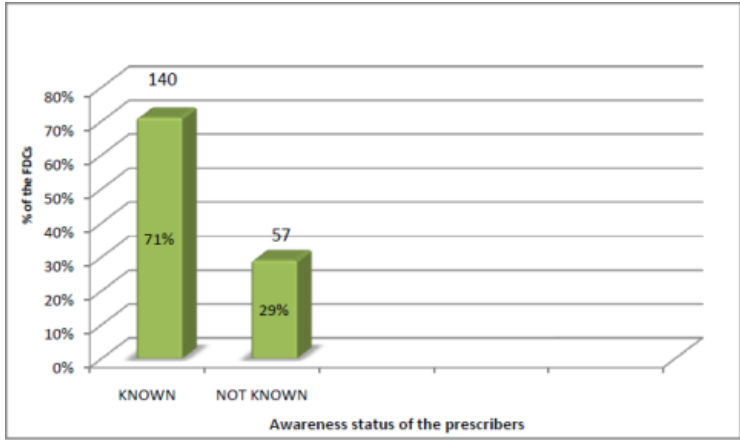

Figure 4: Prescribers awareness about the APIs of FDCs. FDCs are expressed as percentages, APIs=Active pharmacological ingredients, FDC = fixed dose combination, $\mathrm{n}=197$.

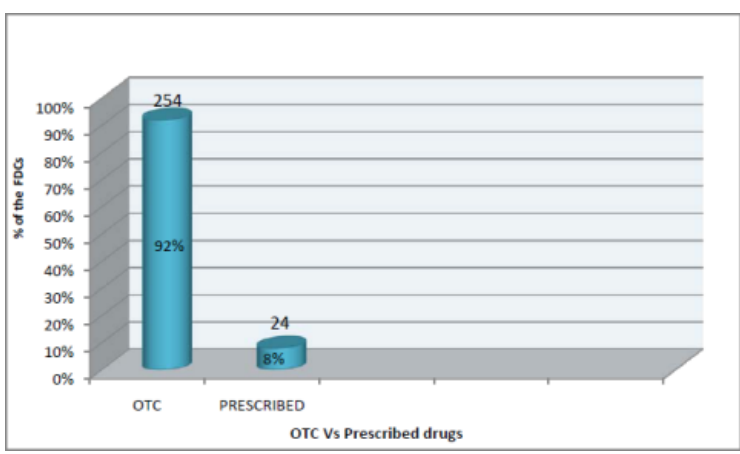

Figure 5: FDCs prescribed which were available OTC and as prescription drugs. FDCs are expressed as percentages, $\mathrm{FDC}=$ fixed dose combination, OTC $=$ Over the counter, $\mathrm{n}=278$.

Table 1: Pharmacological classes of FDCs prescribed with categorization as per WHO guidelines.

\begin{tabular}{|llllll|}
\hline Class of FDC & $\mathbf{n}$ & Rational & Irrational & Absurd & Banned \\
\hline Antimicrobials & 68 & 6 & 55 & 4 & 3 \\
\hline Anti-inflammatory agents & 65 & 0 & 44 & 10 & 11 \\
\hline Nutritional supplements & 48 & 4 & 29 & 9 & 6 \\
\hline Cough and Cold agents & 25 & 0 & 18 & 1 & 6 \\
\hline Ant-ulcers & 12 & 1 & 11 & 0 & 0 \\
\hline Anti-hypertensives & 11 & 0 & 11 & 0 & 0 \\
\hline Hypolipidemics & 7 & 0 & 7 & 0 & 0 \\
\hline Anti-diabetics & 3 & 0 & 3 & 0 & 0 \\
\hline Anti-histaminics & 7 & 0 & 7 & 0 & 0 \\
\hline Digestive enzymes & 3 & 0 & 2 & 0 & 1 \\
\hline
\end{tabular}

$\mathrm{n}=$ number of FDCs prescribed in each pharmacological class, FDC $=$ fixed dose combination. 
Table 2: Banned FDCs prescribed by the physicians during the study period.

\begin{tabular}{|c|c|c|}
\hline $\begin{array}{l}\text { Sr. } \\
\text { No. }\end{array}$ & Banned FDCs & Remark \\
\hline 1 & $\mathrm{~B} 1+\mathrm{B} 6+\mathrm{B} 12$ & $\begin{array}{l}\text { WHO recommends the } \\
\text { intake of vitamins } \\
\text { through diet. }\end{array}$ \\
\hline 2 & $\begin{array}{l}\text { Gatifloxacin } \\
\text { combinations }\end{array}$ & $\begin{array}{l}\text { Gatifloxacin is banned } \\
\text { by WHO in all forms of } \\
\text { formulations. }\end{array}$ \\
\hline 3 & $\begin{array}{l}\text { Levocetrizine }+ \\
\text { Phenylpropanolamine }\end{array}$ & $\begin{array}{l}\text { Latter was banned due } \\
\text { to risk of hemorrhagic } \\
\text { stroke. }{ }^{14}\end{array}$ \\
\hline 4 & $\begin{array}{l}\text { Cough cold } \\
\text { preparations with } \\
\text { Nimesulide }\end{array}$ & $\begin{array}{l}\text { Nimesulide } \\
\text { combinations were } \\
\text { banned due to increased } \\
\text { risk of hepatic toxicity. }\end{array}$ \\
\hline 5 & $\begin{array}{l}\text { FDCs with } \\
\text { Paracetamol 500mg }\end{array}$ & $\begin{array}{l}\text { WHO and CDSCO } \\
\text { recommends use of } \\
\text { paracetamol in the } \\
\text { dosage of } 325 \mathrm{mg} \text { in } \\
\text { FDCs. } 15\end{array}$ \\
\hline
\end{tabular}

$\mathrm{FDC}=$ fixed dose combination

\section{DISCUSSION}

The study evaluated the prescribing trend of FDCs in a tertiary care hospital. Irrational FDCs is a menace worldwide. Presently, exact data reported from India is not known. Hence, the study was carried out to observe the scenario of prescribing FDCs in the Central India. The study showed the trend towards prescribing irrational FDCs. Approximately; eight percent of the FDCs were rational as they fulfilled all the WHO criteria. The most common examples were amoxicillin plus clavulanic acid, sulphamethoxazole plus trimethoprim, pyrimethamine plus sulfadoxine, oral rehydration solutions and artemether plus lumefantrine. Our study had similar findings with previous observations that there was scientific justification for combining ingredients in only 14 FDCs. ${ }^{5}$ Seventeenth WHO essential medicine list (EML) of 2011 contains only 23 FDCs and national list of essential list (NLEM) 2011 contains only 17 FDCs. In this study, there were $94.96 \%$ FDCs which were outside the list of FDCs in the WHO EML and NLEM and were not according to WHO criteria towards rational FDCs. Our study had similar findings with that of previous study who found that out of 130 FDCs prescribed; only 7 were enlisted in the essential medicine list of WHO and Govt. of India 2011. Ninety four percent FDCs were outside this list. ${ }^{5}$

Seventy six percent FDCs were either pharmacologically incompatible or their pharmacokinetic parameters did not match or their APIs interacted with each other or the combination produced increase in adverse reactions. They did not fulfil the WHO criteria for rationality. We shortlisted few of the examples with justification for irrationality. Dicyclomine and paracetamol combination is having same mechanism of action and is highly irrational. Dicyclomine causes loss of sweating and has a high propensity to cause hyperthermia. ${ }^{6}$ Etoricoxib and paracetamol combination of two NSAIDs is not recommended as they offer no additional benefit. ${ }^{7}$ In glibenclamide and metformin combination, glimepiride is to be administered before the meals and metformin is to be administered after the meals. Hence, it is better to administer these drugs separately. In pantoprazole and domperidone combination, the role of prokinetic agent domperidone is not clear as peptic ulcer disease is not always associated with nausea and vomiting. ${ }^{8}$ The combinations of cephalosporins with clavulanic acid is not recommended as cephalosporins are inactivated by class $\mathrm{C}$ beta lactamases or cephalosporinases while clavulanic acid is only active against class A beta lactamases. ${ }^{9}$ The fluoroquinolones with anti-amoebic drugs is not recommended as most of the times; the infection is either bacterial or amoebic and never mixed. The combination of anti histaminic drugs with anti asthmatics (Ambroxol plus Levocetrizine) are not recommended because there are other mediators which play important role in the pathophysiology of asthma. ${ }^{10}$ The FDCs of all topical preparations including combinations of steroids plus antibacterials, antibacterials plus anti fungal and antibacterials plus anti fungal plus steroids are irrational as the patient almost never need all the APIs as the infections are either bacterial or fungal and never mixed. ${ }^{11}$ Nine percent of the FDCs did not have justification or reason for their combination or they showed no increase in efficacy or the second content added was unnecessary. Few of the examples are dextromethorphan and Guaiphenesin/ Terbutaline combination. This combination has antagonizing action as expectorants are functioned to cough out the secretions and dextromethorphan is a cough suppressant. ${ }^{8}$

Nearly nine percent of the FDCs contained banned combinations. ${ }^{12-15}$ Central drug standard control organisation (CDSCO) on $23^{\text {rd }}$ September 2011 issued a circular to all state drug controllers stating not to grant fresh licenses or renewal of licenses of combination products containing paracetamol more than $325 \mathrm{mg}$ per tablet or capsule ${ }^{15}$ but our study witnessed prescribed FDCs containing paracetamol $500 \mathrm{mg}$. Ninety five percent of the FDCs were prescribed by the brand names and only 5\% of the FDCs were prescribed by generic names. Few of the FDCs which were prescribed as generic names were combinations of amoxicillin and clavulanic acid, cotrimoxazole, paracetamol and diclofenac sodium, azithromycin and ambroxol, glibenclamide and metformin. Our study had similar findings corresponding with the previous study which indicate that out of 990 prescriptions screened, 90\% contained only brand names. ${ }^{16}$

Ninety five percent of physicians obtained information about these FDCs through drug detailers, 20\% through seniors, 20\% through colleagues and only 5\% searched the information on FDCs through authentic literature like books, standard journals and standard internet sites. This finding is in concurrence with previous findings 
suggesting that common sources of information about FDCs were medical representatives, colleagues/peers, MIMS/CIMS and Continuous Medical Education (CMEs). ${ }^{17}$ Approximately, three percent of the FDCs were costing more than Rs.500. In $75 \%$ of the FDCs, the individual component was cheap but the combination or the addition of second content increased the cost. FDCs are cost effective only when they are used for certain chronic diseases such as tuberculosis, HIV infections and leprosy. For rest of indications; the addition of second content almost always causes increase in cost. ${ }^{18}$ This finding is parallel with the study supporting that there was marginal increase in the cost when FDCs were used instead of free drug components. ${ }^{19}$

Prescribing more than one drug leads to drug interactions and adverse drug reactions which sometimes may be dangerous and life threatening needing hospitalization, increasing financial burden and reduction in quality of life. $^{20}$ FDC use is justified in conditions such as tuberculosis, malaria, AIDS, leprosy and other clinically relevant chronic conditions, as they increase the adherence to the therapy. ${ }^{21}$ More than one third of new drugs added to the therapeutic armamentarium are FDCs. ${ }^{5}$ Some are very popular and flourishing and experts worldwide express serious concerns about these as most of them are irrational. Such FDCs do not find mention in standard text books, journals etc., but manufacturers rip the benefit of huge sale and hence promote them vigorously by influencing prescribers unethically. $^{20}$ Large number of FDCs are of little importance in terms of essential health care. ${ }^{22}$ Indian Government issues notifications from time to time banning these irrational FDCs, prohibiting their manufacture and sale. Till date 79 formulations have been banned. According to the Drugs and Cosmetics Act, 1940, FDCs are considered as new drugs and finished products needing proper evidence on their efficacy and safety. ${ }^{5}$ Hence, randomized controlled trials may be necessary showing superiority over reference treatment, or reference may be obtained from scientific literature of adequately high quality having high impact factor as it is always not possible to generate fresh data.

Drug regulatory bodies should take urgent action to mitigate and weed out irrational FDCs. New FDCs require clearance from drug controller general of India (DCGI) and state drug controllers. However, they are mostly marketed after the approval of state drug controller's only. ${ }^{21}$ In many irrational FDCs, the potential advantages including increase in efficacy through complimentary mechanism of action, reduced side effects, decrease in resistance, increase in patient compliance, and decrease in cost should be present. But many times, the disadvantages like inflexible fixed dose ratio, incompatible pharmacokinetics, increase in toxicity and allergy, ignorance about the contents are present. Eighty percent of the FDCs did not confirm to the WHO list of FDCs. Critical appraisal by practitioners, scientists, regulatory authorities is the need of hour to weed of these irrational FDCs from the market. ${ }^{5}$

Clear objective should be to prescribe generic FDCs with correct dose and duration, considering appropriate information to the patient. Unethical promotional activities by the manufacturers not only influence the prescribers, but also the retailers, homeopaths, ayurvedic practitioners to prescribe or sell FDCs. There is no formal training for undergraduates, post graduates or CMEs for practitioners, no proper drug information centres for the physician or patient use. Health care professionals should keep themselves updated about irrational drugs and banned drugs by the DCGI. ${ }^{5}$ There is also a need for sensitization of the under graduate and post graduate students about the rational FDCs. The pharmacological basis of combining each ingredient in the formulation should be taught. Selection of $\mathrm{P}$ drugs, rational drug use, use of rational drug combinations and ethical laboratory practices should be inculcated in the student's curriculum during their clinical training. ${ }^{23}$ However; some combinations could be rational, provided it fulfils the WHO criteria and could be applied to larger populations. Further studies are warranted to substantiate our findings.

\section{CONCLUSION}

In conclusion, patient cannot have access to rational FDCs and they are not always prescribed by the prescribers. Many doctors were ignorant about the essential drugs. Physicians and regulators should get alerted in time and regulatory actions or government laws should be made mandatory. Manufacturers are in business of profit but they should self regulate themselves and should follow the moral code of conduct thinking in larger perspective of community health and health of nation as use of irrational FDCs result in non-eradication of diseases, spread of resistance, chronic persistence of unhealthy, unproductive population, wastage of precious government resources, under development of nation and economic down growth. Availability of minimum essential medicines, presently 348 , for basic health care are most efficacious, safe, cost effective, and should be the priority of any government and every citizen should have the basic right of access to these essential medicines.

\section{Funding: None \\ Conflict of Interest: None declared \\ Ethical Approval: The study was approved by the local institutional ethics committee}

\section{REFERENCES}

1. WHO drug information volume 17 [internet]. Geneva: WHO; 2003. Available at: http:// apps.who.int/medicinedocs/en/d/Js4955e/7.html.

2. Baiardini. I, Guerra. L, Pasquali, M, Bonadonna. P, Pasalaqua. G, Canonica. G.W. Quality of Life in Patients with Adverse Reactions to Drugs: 
Preliminary Results from A New Questionnaire. J Allergy Clin Immunol 2004;113(2):s70.

3. WHO technical report series. WHO expert committee on specifications for pharmaceutical preparations- thirty ninth report. Geneva: WHO; 2005.

4. Jain NK, Akarte A, Deshmukh PT , Kannojia P, Garud N , Yadav A. rationality of fixed dose combinations: An Indian scenario. The Pharma Research 2009; volume 01: 158-68.

5. Hindoliya M, Sharma PK, Dhaneria SP. Prescribing Trends of Fixed Dose Combinations in Teaching and Non Teaching Hospitals of Ujjain District. Journal of Pharmacy Research 2012; Volume 5(7): 3503-3505.

6. Tripathi KD. Essentials of medical Pharmacology. $6^{\text {th }}$ edition. New Delhi; Jaypee brothers Medical Publishers (P) Ltd, 2008.

7. Hiller A, Silvanto M, Savolainen S, Tarkkila P. Propacetamol and diclofenac alone and in combination for analgesia after elective tonsillectomy. Acta Anaesthesiol Scand. 2004 Oct; volume 48(9): 1185-9.

8. Dhaneria SP. Rational and Irrational Drug Combinations. Drug Bulletin 2010 April; volume 35(2): 1-15.

9. Chambers HF, Deck DH. Beta-Lactam \& other Cell Wall- \& Membrane- Active Antibiotics. Basic and Clinical pharmacology by Bertram G. Katzung. $11^{\text {th }}$ edition.New Delhi: Tata Mcgraw- Hill education private Ltd, 2009. Pg 773- 793.

10. Boushey HA. Drugs used in asthma. Basic and Clinical pharmacology by Bertram G. Katzung. $11^{\text {th }}$ edition. . New Delhi: Tata Mcgraw- Hill education private Ltd, 2009. Pg 339- 356.

11. Robertson D, Maibach H. Dermatologic Pharmacology. Basic and Clinical pharmacology by Bertram G. Katzung. $11^{\text {th }}$ edition. . New Delhi: Tata Mcgraw- Hill education private Ltd, 2009. Pg 1047 1065.

12. Deshmukh P, Purohit S. Rationality of Fixed Dose Combinations: Necessity to Weed out the Irrational Combinations Mushrooming in Pharmaceutical Industry. Pharmaceutical Reviews 2008; volume $6(1)$.

13. Government of India- Ministry of Health \& Family Welfare (MOHFW). Notification G.S.R
218(E)[internet]. New Delhi: Government of India; 2011 March 16. Available at http://www.cipi.in/GSR218(E).pdf.

14. Government of India- Ministry of Health \& Family Welfare (MOHFW). ). Notification G.S.R 82(E)[internet]. New Delhi: Government of India; 2011 February 10. Available at http:// www.cipi.in/Notification\%20GSR\% 2082(E).pdf.

15. CDSCO. Limitations of acetaminophen (paracetamol) in prescription combination products and giving box warning about its liver toxicity [internet]. New Delhi: CDSCO; 2011 September 23. Available at http://www.cipi.in/DCGI\%20CIR23092011.pdf.

16. Patel V, Vaidya R, Naik D, Borker P. Irrational drug use in India: a prescription survey from Goa. J Postgrad Med. 2005 Jan-Mar; volume 51(1): 9-12.

17. Goswami NN, Patel PP, Gandhi AM, Dikshit RK. An evaluation of knowledge, attitude and practice about fixed dose combinations in resident doctors. IJP. 2011; volume 43(7): 41-197.

18. WHO. Proposal of listing FDCs for infectous diseases [internet] WHO. Available at : http://archives.who.int/eml/expcom/children/Applic ations/ Monday_2_FDC.pdf.

19. Rathnakaru $\mathrm{p}$ et al. Prescribing patterns of fixed dose combinations in hypertension, diabetes mellitus and dyslipedimia among patients attending a cardiology clinic in a tertiary care teaching hospital in india. PharmacieGlobale (IJCP) 2011, volume $6(05)$.

20. Chandler SC, Lekha S. Fixed dose drug combinations (FDCs): rational or irrational: a view point. Br J Clin Pharmacol. 2008 May; volume 65(5): 795-796.

21. Fixed dose combinations. Rational drugs- an update on rational drug use. January- June 2008; issue 3132.

22. Chakraborti A. Fixed dose combinations in therapy [internet]: pharma voice; 2007 August. Available from http://www.expresspharmaonline .com/20070815/research02.shtml.

23. Gautam CS, Aditya S. Irrational drug combinations: Need to sensitize undergraduates. Indian J Pharmacol 2006;38:169-70.

doi:10.5455/2319-2003.ijbcp20130820

Cite this article as: Rayasam SP, Dudhgaonkar SS, Dakhale GN, Hire RC, Deshmukh PS, Gaikwad NN. The irrational fixed dose combinations in the Indian drug market: an evaluation of prescribing pattern using WHO guidelines. Int $\mathrm{J}$ Basic Clin Pharmacol 2013;2:452-7. 